\title{
The Elaphidion Audinet-Serville of the Puerto Rican Bank: new species, distribu- tions, taxonomic corrections, and a key to species (Coleoptera: Cerambycidae: Elaphidiini)
}

\author{
MICHAEL A. IVIE ${ }^{1} \&$ MICHELLE L. SCHWENGEL-REGALA ${ }^{2}$ \\ ${ }^{1}$ Montana Entomology Collection, Montana State University, P.O. Box 173020, Bozeman, MT 59717-3020; corresponding author: \\ mivie@montana.edu \\ ${ }^{2}$ Department of Malacology, Natural History Museum of Los Angeles County, 900 Exposition Blvd., Los Angeles, CA 90007
}

\begin{abstract}
The six species of Elaphidion Audinet-Serville occurring in Puerto Rico and the Virgin Islands are keyed, illustrated and diagnosed. Elaphidion michelii Ivie NEW SPECIES (Puerto Rico) and Elaphidion mayesae Ivie NEW SPECIES (St. Thomas and Puerto Rico) are described. Previous records for E. pseudonomon Ivie for Puerto Rico are corrected to Elaphidion mayesae Ivie.
\end{abstract}

Key words: Longhorns, West Indies

\section{Introduction}

In 1985 Ivie published an attempt to clarify the taxonomic status of various West Indian members of the Elaphidiini. One taxonomic innovation of that paper was the unraveling of several names proposed for two cryptic species of Elaphidion Audinet-Serville occurring in the Virgin Islands. It was discovered that five available names all referred to Elaphidion glabratum (Fabricius) of St. Croix and the Lesser Antilles, while the common species in the northern Virgin Islands (i.e. those lying on the Puerto Rican Bank) actually lacked a valid name. This latter species was named Elaphidion pseudonomon Ivie. The type locality was designated as Red Hook, St. Thomas, but paratypes were included from St. John, Tortola, Virgin Gorda, and Anegada. Unfortunately, four specimens from Roosevelt Roads, Puerto Rico, were also included in the paratypes of $E$. pseudonomon.

Discovery of a new but related Elaphidion species in a unique pocket of wet forest near the very top of St. Thomas' second highest peak led to a reexamination of E. pseudonomon. Clarification of the characters involved led to the discovery that the Puerto Rican specimens included in the type series of E. pseudonomon in fact belong to this closely related undescribed species. Additional Puerto Rican specimens have been examined that confirm this conclusion.

We take this opportunity to describe this species, clarify the diagnoses of the three very similar species that occur in Puerto Rico and the Virgin Islands, as well as describe a second, more distantly related new member of the genus from Puerto Rico, and provide a key to the congeners from these Islands. 


\section{Materials and Methods}

Distributions are taken from Blackwelder (1946), Villiers (1980), Ivie (1985), Browne et al. (1993), Lingafelter and Micheli (2004), Valentine and Ivie (2005), and Chalumeau and Touroult (2005), except as noted by a citation in the list of islands. Inclusion of a collection coden after an island name indicates a new record not documented by one of the above references, with the voucher to be found in the cited collection. Label data on types are presented exactly as on the label, a change of line indicated by a semicolon (;) and a new label by a slash (/). Length is measured from the front of the antennal tubercles to the tip of the elytral spines.

Material was received from the collections listed below. Repositories for material studied are indicated by the associated codens.

EAPR Museo de Entomología y Biodiversidad Tropical de la Estación Experimental Agrícola, University of Puerto Rico, Río Piedras, PR. Rosa Franqui.

ERPL Department of Biology, University of Puerto Rico, Mayagüez, PR. Angel Berríos, Nico Franz.

FSCA Florida State Collection of Arthropods, Gainesville, FL. Robert. E. Woodruff.

JAMC Julio A. and Charyn J. Micheli, private collection, Ponce, PR.

MIZA Museo del Instituto de Zoología Agrícola, Universidad Central de Agricultura, Maracay, VENEZUELA. Luis Joly.

MNRJ Museu Nacional, Rio de Janeiro, BRAZIL. Miguel A. Monné.

NMNH National Museum of Natural History, Washington, DC. Steven W. Lingafelter.

WIBF West Indian Beetle Fauna Project, Montana State University, Bozeman, MT. Michael A. Ivie

\section{Taxonomy}

\section{Elaphidion conspersum Newman}

(Fig. 14)

Elaphidion conspersum Newman,1841: 110. Ivie, 1985: 309. Browne et al., 1993: 44. Monné and Giesbert, 1995: 54. Chalumeau and Touroult, 2005: 96. Monné and Hovore, 2005: 65. Valentine \& Ivie 2005:280. [For a complete pre1985 synonymy, see Ivie 1985.]

DIAGNOSIS: The bispinose antennae and pronotum with the median callus broadly connected to the base of the pronotum will distinguish this species from all others in the region. Length $18-25 \mathrm{~mm}$.

DISTRIBUTION: Bahama Is. (Crooked, Long, Great Exuma, New Providence, Nassau [WIBF] San Salvador [WIBF]); Cuba, Hispaniola, Puerto Rico, St. Thomas, St. John, Guana, St. Croix, Anegada [WIBF], St. Martin, Guadeloupe (Grande-Terre, Basse-Terre, Désirade), Curação, Bonaire.

BIOLOGY: Chalumeau and Touroult (2005) list Hippomane manchinella L. as a host of this species.

\section{Elaphidion michelii Ivie, new species}

(Figs 12-13)

Elaphidion irroratum [not Linnaeus], Wolcott, 1946: 336 [misidentification, part?].

This striking species has been known for many years, but never named. The exceptionally large and oddly patterned specimen that Wolcott (1946) referred to as E. irroratum may have belonged to this species. Elaphidion michelii is the largest member of the genus found in the United States, and is tied with Elaphidion 
excelsum Gahan from Guadeloupe as the largest member of the genus. That it has remained undescribed for so long seems related to its rarity in collections. Only eight scattered specimens have been located, the most recent collected in 1972, in spite of several workers specifically searching for the species in the last two decades. It is widespread on the island, having been taken from Mayagüez and Lajas in the southwest to Toa Baja on the north coast near San Juan. It has never shown up in the extensive collections made near Ponce by J. Micheli, nor in the El Yunque region where so many visitors to the island collect.

DIAGNOSIS: By far the largest species of the genus on the Puerto Rican Bank, the size alone (= $30 \mathrm{~mm})$ will distinguish this species from all but the very largest $E$. irroratum (up to $30 \mathrm{~mm}$ ). The bispinose antenna and pronotum with the median callus divided and not or only very narrowly connected to the base of the pronotum will distinguish this species from all other Elaphidion in the region.

DESCRIPTION: With the characteristics of Elaphidion (Lingafelter 1998).

MALE (Fig. 12): Elongate subparallel; reddish brown, with golden recumbent pubescence of two types those arising from distinct punctures and those placed between these punctures, the latter dense around eyes, between callosities of pronotum, on scutellum, and in scattered patches on elytra. Eye emarginate, encompassing base of antenna. Antenna (Fig. 12); tenth antennomere reaching elytral apices; third antennomere reaching base of elytra; fourth antennomere subequal to length of third, 3-4 bispinose apically, 5 weakly spined mesally, dentate laterally; 6-8 externally dentate; eleventh longer than third; 3-11 carinate externally, weak on 3 and 4, strong thereafter; 4-11 longitudinally canaliculate dorsal to this carina, groove on 5-11 margined dorsally by carina. Pronotum wider at base than apex, lateral margin expanded immediately behind apex, weakly arcuate basal submarginal groove; apical margin with narrow submarginal groove; basal margin with complete submarginal groove; median gibbosity at anterior median 1/4, crossed longitudinally by narrow anterior extension of bare, shining median longitudinal callus, this longitudinal callus widened medially, not reaching posterior margin; disc with pair of calli bracketing median callus, these calli in the form of the numeral "7"; additional callus laterad and parallel to the stem of the "7"; rest of disc and lateral area weakly rugose. Elytra smooth between irregularly placed punctures, each puncture with indistinct seta; irregular small patches of appressed setae mesad humeral umbo, along lateral margin and on disc; apices bispinose, spine subequal. Prosternal sculpture and vestiture similar to that of lateral portions of pronotum, except intercoxal processes and apical collar smooth, nearly glabrous. Femora not clavate; apices of metafemora acutely dentate, others rounded. Length: $30 \mathrm{~mm}$.

FEMALE (Fig. 13). Differs from the male in having a slightly broader body, the pronotal calli gibbose, the pronotum far more rugose, much shorter antennae that reach the third ventrite, and the last antennomere short and broad (Fig. 13a). Length: 30-38 mm.

DISTRIBUTION: Puerto Rico.

TYPES: HOLOTYPE MALE: Toa Baja, P. R.; Jan 1940; Coll. P. Sostre (from ERPL, deposited in NMNH with permission of the curator).

PARATYPES: 1 FEMALE-Same data as Holotype (MIZA); 1 FEMALE-Mayagüez, PR; Oct-Dec 1965; Coll. M. S. Torres (JAMC); 1 FEMALE—PUERTO RICO; Lajas; 6-IV-72; S. García (WIBF); 1 FEMALE-PUERTO RICO; 1968; V. C. Blackburn (FSCA); 1 FEMALE_PUERTO RICO; 2 May 1961; R. W. Husband (WIBF); 1 FEMALE—Cataño; Puerto Rico; 6.III.1948—Rosado col./ Coleção Campos Seabra (MNRJ on loan to NMNH).

An additional female specimen (not a paratype) has been reported to me by Julio Micheli of Ponce, but was not available for study in time for inclusion as part of the type series. Although I have not seen this specimen, I have no doubt that it belongs to this species. The data he provided to me are: Cabo Rojo, P.R.; 4 April 1937; Coll: R.A. Irizarry [JAMC].

ETYMOLOGY: A noun in the genitive case, in honor of the dean of Puerto Rican coleopterists, Julio A. Micheli of Ponce, in recognition of his many contributions to the study of his native island and his kindnesses to colleagues. 


\section{Elaphidion mayesae Ivie, new species}

(Figs 3-10)

Elaphidion glabratum [not Fabricius]: Wolcott, 1951: 338.

Elaphidion pseudonomon Ivie, 1985: 312, in part [Puerto Rican paratypes only]. Monné and Giesbert, 1995 : 55 in part [Puerto Rican record only]. Monné and Hovore, 2005: 66, in part [Puerto Rican record only].

Elaphidion n. sp. (Ivie in prep.): Lingafelter and Micheli, 2004: 50.

Elaphidion sp.: Chalumeau and Touroult, 2005: 103.

Discovery of this species was a real surprise, given the long and extensive study of the insect fauna of St. Thomas, Virgin Islands, and Puerto Rico. The type series was taken in a light trap located in a dense forest on the north side of St. Thomas, near the top of St. Peter Mountain. This tiny spot is the wettest point on the island, and is the only known Virgin Islands locality for three cerambycids also otherwise known only from Puerto Rico (E. mayesae, Linsleyonides portoricensis Fisher and Cacostola leonensis Dillon and Dillon, vouchers in WIBF). Very extensive trapping and collecting on other parts of St. Thomas has never yielded E. mayesae, although hundreds of E. pseudonomon have been examined from virtually every other part of the island, and from many other islands in the northern Virgin Islands.

The populations on Puerto Rico are also limited to wet forests. Specimens of the Puerto Rican population are not included in the type species, as they differ somewhat from those from St. Thomas (see diagnosis below). All previous Puerto Rican records for Elaphidion glabratum and Elaphidion pseudonomon almost certainly belong here, and the paratypes mistakenly included in the original description of E. pseudonomon are now placed here.

DIAGNOSIS: Elaphidion mayesae is divided into two populations that may eventually be considered sister-species. Extensive attempts to find consistent characters to distinguish them failed, however, and in every case at least one exception could be found. Therefore, they are considered vicariant populations of a single species, probably separated since the rising sea levels after the Pleistocene eustastic minimum divided the islands of the Puerto Rican Bank. Within the Puerto Rico-Virgin Islands region, E. mayesae is most similar to the E. glabratum/pseudonomon species pair, but is easily distinguished from them by the fourth antennomere short relative to the third and fifth (Figs 3-6). They also have the metafemur distinctly spined, rather than the dentiform condition of the E. glabratum/pseudonomon species pair.

Elaphidion mayesae will imperfectly key to Elaphidion bahamicae Cazier and Lacy in Gilmour's (1968) key to West Indian Elaphidion, because of the shared short fourth antennomere. However, this is more exaggerated in E. bahamicae, which is also much narrower-bodied (elytra $3 \times$ as long as width across humeri vs $2.5 \times$ in E. mayesae), and has the anterolateral pronotal calli black and weakly longitudinally carinaform, rather than concolorous and rounded as in E. mayesae. The elytral setae of E. bahamicae are denser, while in E. mayesae they are patchier.

The St. Thomian and Puerto Rican populations differ in overlapping relative characters. When the intact antenna is directed posteriorly, the apex of the main stem of the third antennomere does not reach the basal margin of the pronotum in the typical population, but reaches the base of the elytron in the great majority of Puerto Rican specimens. St. Thomian specimens are, on average, somewhat darker, tending towards a piceous-brown, while the Puerto Rican form is a more classic castaneous. The prosternum between the procoxae and anterior collar is more distinctly transversely rugose in those from St. Thomas, while the Puerto Rican population is usually almost totally smooth. The profemora of the Puerto Rican specimens are more heavily clavate than those from St. Thomas, and the hind femora are more strongly arcuate above.

The male genitalia of the two populations are highly variable and overlap in form. The range of variation is shown in Figs 7-10. In general, those from Puerto Rico tend to be more elongate with the lateral margins of the apical portion of the aedeagus sinuate (Fig. 9) and the distance between the basal and apical notches of the parameres rather long (Fig. 10). Those from St. Thomas tend to be shorter and broader, with the lateral mar- 
gins of the apical portion of the aedeagus straight (Fig. 7) and the distance between the basal and apical notches of the parameres rather short (Fig. 8). However, both populations have individuals that exhibit all the forms, and genitalia cannot be used to distinguish them.

This situation is complicated by variation that is similar to the major/minor male variation so common in the Scarabaeidae, especially so in the Puerto Rican population. This variation is exhibited in the punctation of the pronotum and length of the male antenna relative to the total length of the body. Many cerambycid species are characterized by the length of the antenna relative to the body (cf. Linsley 1963). In E. mayesae, the length of the male antenna is quite variable. The antennomere that reaches the apex of the elytron varies in this species from the midpoint on number 8 to the midpoint of antennomere 10. Males with short antennae usually have the pronotum like the female condition, i.e. more heavily punctate and rugose, than those with longer antennae. The carinae of the antennae are more distinct in the longer-antenna specimens, and the relative length of the last antennomere increases out of scale with the total length, so that it varies from shorterthan to longer-than the scape. Interestingly, the shorter-antenna form has relatively stronger spines on the antennomeres.

DESCRIPTION: With the characteristics of Elaphidion, (Lingafelter 1998).

MALE: Elongate subparallel; dark chocolate brown, densely covered with golden recumbent pubescence of two types - those arising from distinct punctures and those placed between these punctures. Eye emarginate, encompassing bases of antenna. Antennae (Fig. 3) variable in relative length, ninth or tenth antennomere reaching elytral apices; third antennomere only rarely reaching base of pronotum; fourth antennomere $1 / 2-2 / 3$ length of third, 3-5 spined meso-apically, 6 sometimes apically dentate; spine of third $3 / 4$ or more length of fourth; eleventh equal to or shorter than third; 5 or 6-11 weakly carinate externally. Pronotum very slightly wider at base than apex, arcuate laterally; apical margin with narrow submarginal groove, incomplete medially; basal margin with deep, complete, submarginal groove; disk with bare, shining median longitudinal callus, narrowly complete at anterior margin, more broadly complete to posterior margin; disc laterally with pair of calli on shared slight swelling 1/3 distance from apical margin, arranged transversely with mesad callus larger, nearly round, smooth, impunctate, separated from laterad callus by band of appressed transverse setae, laterad callus round to oblique; additional lateral smooth glabrous calli behind anterior pair, reaching basal groove; rest of disc and lateral area punctate, punctures varying from coarse ocellate punctures to fine, simple punctures. Scutellum setose laterally, with bare median line. Elytra only weakly sculptured; raised areas more often rubbed of dense pubescence, leaving a highly variable pattern that often includes a narrow longitudinal band just mesad humerus and a broad area on central disc; each puncture in this rubbed area with a single scale-like seta remaining; apices bispinose, outer spine slightly longer. Prosternum smooth mesally from intercoxal processes to submarginal groove. Profemur only weakly clavate, in frontal view maximum width $2 \mathrm{X}$ width at distal end of trochanter. Apices of meso and metafemora distinctly spinose, spine narrow, acute, subequal in length to apical width of tibia. Genitalia variable, usually as in Figs. 7-8, but variation extending to 9-10. Length: 11-13 mm.

FEMALE: Differs from the male in having a slightly broader body, larger diameter pronotal punctation, shorter antennae not surpassing elytral apices, a shorter fourth antennomere and the last antennomere being short and broad (Figs 4, 6). Length: 11-14 mm.

VARIATION: Members of the Puerto Rican populations exhibit the following variation not seen in typical specimens from the Virgin Islands. Color reddish-brown. MALE: Antenna (Fig. 5) variable in relative length, eighth, ninth or tenth antennomere reaching elytral apices; third antennomere reaching base of elytron; fourth antennomere up to 3/4 length of third, 6 spined; eleventh shorter than third. Pronotum with a very slight indication of a rounded angle at midpoint; median longitudinal callus, narrowly complete at anterior margin, more broadly complete to posterior margin; laterad callus longitudinal-obliquely elongate, semi-carinate, sometimes indistinct, sometimes posteriorly connected to mesad callus by narrow band. Elytra weakly depressed along suture in basal $1 / 4$ and in apical $1 / 2$; weakly longitudinally gibbous postero-laterad of scutellum, 
this raised area reaching suture between sutural depressed areas; narrow depression laterad of this in basal 1/2; behind humerus very weakly longitudinally raised, joining other raised areas in median portion of elytron. Length: 9-15 mm. FEMALE. Length: 11-14 mm.

DISTRIBUTION: Known only from wet forest on the north side and near the top of St. Peter Mountain, St. Thomas, Virgin Islands and wet forests of Puerto Rico.

TYPES. HOLOTYPE MALE : VIRGIN IS: St. Thomas; Est. St. Peter, ca 1450ft; 3-H-4 North Star; 04JAN-30 JUNE 1983; Carol Mayes, u.v.light/ WIBF 021377 (from WIBF, deposited in NMNH).

PARATYPES: 5 MALES, 9 FEMALES-Same data as Holotype, WIBF 021379-82, 84-88, 90-95 (WIBF).

ADDITIONAL MATERIAL STUDIED BUT NOT INCULDED IN TYPE SERIES: 3 MALES, 2 FEMALES-PUERTO RICO: El Verde, 250m; 22 SEP 1987; M. A. Ivie, at light; 3 MALES, 5 FEMALESibid., 23 SEP 1987; 1 MALE, 1 FEMALE-ibid., 24 SEP 1987; 1 MALE-ibid., 25 SEP 1987; 1 MALE, 2 FEMALES—ibid., 26 SEP 1987; 4 MALES, 2 FEMALES—ibid., 27 SEP 1987 (WIBF). 2 MALESPUERTO RICO: Caribbean; National Forest, base of; El Toro trail, 600 meters; $18^{\circ} 16^{\prime} 55^{\prime \prime} \mathrm{N}, 65^{\circ} 51^{\prime} 10^{\prime \prime} \mathrm{W}$; tree cut - 26 June 2002; Steven W. Lingafelter (NMNH). 1 MALE, 1 FEMALE -PUERTO RICO: Caribbean; National Forest, Road 186 at; Km 14.4, Rio Grande bridge; 18¹7’50”N, 6550’33”W; 475 meters, 27 June 2000; dead tree cutting; Steven W. Lingafelter (NMNH). 1 FEMALE-ibid, Charyn J. Micheli (JAMC). 2 FEMALES—PUERTO RICO: Maricao For; Near Cabins, 850-900m; 1808’45”N, 6558'52”'W; 19 June 2002, Lights; Steven W. Lingafelter (NMNH). 1 FEMALE —ibid., Norman Woodley (NMNH). 1 FEMALE-ibid., 17-18 June 2002, at lights, Charyn J. Micheli (JAMC). 2 MALES, 1 FEMALE PUERTO RICO: Bosque Estatal; de Guajataca, along Road 446; 18²5’00”N, 6558’30”W; 20 June 2003/ Beating veget.; Steven W. Lingafelter (NMNH). 1 FEMALES-PUERTO RICO: Ponce; Rd. 132, km 20; X22-1976; J. Micheli/ at light (NMNH). 1 MALE-PUERTO RICO: Rd 10 Km 24; VI-8-1977; J. Micheli (NMNH). 1 MALE-PUERTO RICO: Rd $10 \mathrm{Km} \mathrm{24;} \mathrm{5/11-XI-1978;} \mathrm{J.} \mathrm{Micheli;} \mathrm{blacklight} \mathrm{trap} \mathrm{(JAMC).} 1$ MALE , 2 FEMALES -PUERTO RICO: Rd 10 Km 24; 1/7-V-1978; J. Micheli; blacklight trap (JAMC). 1 MALE-ibid., 5/11-XI-1978; J. Micheli; (JAMC). 1 FEMALE-Unknown host; Central Rufina; Ponce, P.R.; coll. 11 Dec. '33; R. G. Oakley (NMNH). 1 FEMALE-Mayagüez, P.R.; 190 [sic] (NMNH). 1 MALE—ibid., II-7-1912/ F. W. Hooker collector (NMNH). 1 FEMALE-El Yunque; 800 ft., PR/Feb; 21.00/ C. W. Richmond; collector (NMNH). 1 FEMALE-Bayamon; PR, I-27-34; Lesene \&; Anderson/ San Juan; No. 5130. 1 FEMALE-Puerto Rico; Santurce; X-13-'35; Sta. 65; Blackwelder (NMNH). 1 FEMALE-Flight; Ponce, P.R.; D.DeLeon, v.2.'40/ Hopkins US; 33100-A-9 (NMNH). 1 FEMALE-Roosevelt Rds; Puerto Rico; unknown; A.B. Cochran/ 4 March 1963; San Juan, P.R.; [no. symbol] 18392; 637416 (NMNH). [The next four specimens were included in error with the paratype series of E. pseudonomon by Ivie (1985). They bear the paratype labels of both species]. 3 MALES, 1 FEMALE Roosevelt Rds; Puerto Rico; unknown; A.B. Cochran/ 4 March 1963; San Juan, P.R.; no.18392; 637416 (NMNH).

ETYMOLOGY: A noun in the genitive case, named in honor of Dr. Carol H. Mayes, Director, U.S. Virgin Islands Program in The Nature Conservancy's Caribbean Region, who kindly ran the trap that yielded this species under the porch of her house in the wettest forest on St. Thomas.

\section{Elaphidion irroratum (Linnaeus)}

(Fig. 15)

Cerambyx irroratus Linnaeus, 1767: 633.

Elaphidion irroratum: Linsley, 1963: 83. Zayas, 1975: 90. Villiers, 1980: 285. Browne et al., 1993: 45. Lingafelter and Micheli, 2004: 50. Chalumeau and Touroult, 2005: 97. Valentine \& Ivie 2005:280. [For more complete synonymy, see Linsley, 1963 and Villiers, 1980.]

DIAGNOSIS: The distinct white setose patches on a dark brown background will distinguish this species from other Elaphidion in the region. It is also rather large $(11-30 \mathrm{~mm})$, and has unispinose antennae. 
DISTRIBUTION: North America; Bahama Islands (North Bimini, South Bimini, Andros, Mayaguana [WIBF], Fortuna [WIBF], Crooked [WIBF], Acklins [WIBF], Great Exuma [WIBF], New Providence, Eleuthra, Cat, Long, and Nurse and Buena Vista Cays [Rugged Island Group] [WIBF]); Cuba, Isla de la Juventud, Jamaica, Hispaniola, Mona, Puerto Rico, St. Thomas [WIBF], St. John [WIBF], Tortola [WIBF], Guana; Great Camanoe [WIBF], Anegada [WIBF], St. Croix [WIBF], Buck Is. [WIBF], St. Barthelémy, St. Martin, St. Christopher, Guadeloupe (Grande-Terre, Basse-Terre), Curaçao, Bonaire. Chalumeau and Touroult (2004) have begun the process of describing the different island variants of this species as subspecies, placing the Puerto Rican and Virgin Islands populations under the name E. irroratum debieni Chalumeau and Touroult.

BIOLOGY: This species was reared from a dead log of Albizia lebbeck (L.) Benth. at Ponce in 1939 (Martorell 1976). Chalumeau and Touroult (2005) list hosts of Spondias purpurea L., Rhizophora mangle L., Hippomane mancinella L., Haematoxylon campechianum L., and Laguncularia racemosa (L.) Gaertn.

\section{Elaphidion glabratum (Fabricius)}

(Figs 16, 18 20)

Stenocorus glabratus Fabricius, 1775: 180.

Elaphidion glabratum: Ivie, 1985: 310. Monné and Giesbert, 1995: 54. Chalumeau and Touroult, 2005: 101. Monné and Hovore, 2005: 65. [For a complete pre-1985 synonymy, see Ivie 1985.]

A complete discussion of the tortured nomenclatural history of this species was given by Ivie (1985).

DIAGNOSIS: The small size $(8-19 \mathrm{~mm})$, cinerous to golden pubescence, and relatively long unispinose antennomere 4 will distinguish this species and E. pseudonomon from all other Elaphidion in the area. Although long series of these two closely-related species are obviously distinct to the naked eye when placed next to each other, actual diagnoses of E. glabratum and E. pseudonomon are difficult, and require careful use of details. From E. glabratum, E. pseudonomon, can be distinguished by the male genitalia (see Ivie 1985), somewhat lighter color, details of the antennal configuration and setation. The antennal characters require detailed measurements. In male E. glabratum antennomeres 3 and 4 are subequal (with 4 only rarely more than $1 \mathrm{~mm}$ shorter than 3), and 5 is longer (by $1-3 \mathrm{~mm}$ ) than 3 (i.e. antennomere 4 is greater than $30 \%$ total length of $3+4+5$ ). In male E. pseudonomon, antennomere 3 and 5 are subequal, with 5 no more than $1 \mathrm{~mm}$ longer than 3 , while 4 is at least $2 \mathrm{~mm}$ shorter than 3 (i.e. antennomere 4 is less than $30 \%$ total length of $3+4+5$ ). In females of both species, antennomere 4 is consistently shorter than 3, and in E. pseudonomon it is slightly more so, but the difference is difficult to quantify. In female E. pseudonomon, antennomere 4 is usually less that $28 \%$ of the total $3+4+5$, while in E. glabratum it is usually greater than $28 \%$. For unassociated females, the allopatric distribution is helpful, with E. pseudonomon occurring on the Virgin Islands that lie on the Puerto Rican Bank, while E. glabratum occurs from St. Croix and its satellites into the Lesser Antilles.

The elytral setation and punctation are also different, and helpfully not sexually dimorphic. The setae of E. pseudonomon (Figs 17, 19) are more golden and individually larger than in E. glabratum (Figs 16, 18), covering the elytra and pronotum more uniformly, but not being dense enough to completely obscure the underlying cuticle. The specimen therefore looks uniformly lighter colored to the unaided eye because of the uniform mix of the color of setae and cuticle. In fresh specimens, the humerus is covered in setae (Fig. 17), and at mid-elytron (at the level of the metacoxa) the setae uniformly cover the entire disc except for 2 narrow, indistinct strial lines (Fig. 19). Older rubbed specimens of E. pseudonomon may exhibit bare spots, but never to the extent seen in E. glabratum, and the remaining setal patches are always sparse enough to see through to the surface. This characteristic is always distinguishable at a point just mesad the humeral umbone (Fig. 17), and on the mid-point of the elytron at the level of the metacoxa (Fig. 19). Greasy specimens may appear 
darker, but this is an obvious artifact of preservation. The setae in E. glabratum are cinerous and narrower, and form dense patches that at least in part completely obscure the cuticle (Figs 16, 18), leaving other areas bare except for the single seta associated with each puncture. The difference in setal density of these patches relative to the condition in E. pseudonomon is always distinguishable at a point just mesad the humeral umbo (Fig. 16), and on the mid-point of the elytron at the level of the metacoxa (Fig. 18). The overall effect of this condition is more areas of unobscured cuticle showing to the naked eye, thus making the fresh specimen look darker.

Lastly, post-humeral punctures of E. pseudonomon are usually slightly smaller in diameter, making them seem less dense (Fig. 21). In E. glabratum the post-humeral punctures of the elytra are slightly larger (Fig. 20), although there seems to be about the same number of actual elytral punctures in both species.

DISTRIBUTION: St. Croix, Buck Is. (near St. Croix, WIBF), Saba (WIBF), St. Martin, St. Barthelémy, St. Eustatius, Nevis, Antigua, Montserrat, and Guadeloupe, and probably St. Christopher, Dominica and St. Lucia

Elaphidion pseudonomon Ivie

(Figs 1, 2, 11, 17, 19, 21)

Elaphidion pseudonomon Ivie, 1985: 312. Monné and Giesbert, 1995: 55. Monné and Hovore, 2005: 66. Valentine \& Ivie 2005:280. [For a complete pre-1985 synonymy, see Ivie 1985.]

Elaphidion glabratum pseudonomon: Chalumeau and Touroult, 2005: 103.

This species has been a problem to distinguish throughout its more-than-100-year history (Ivie 1985). When two unit trays of 50 specimens each are placed side-by-side, the difference between E. pseudonomon and $E$. glabratum is so obvious that no one would question their distinctiveness. However, when faced with diagnosing these two highly variable species in such a way that every specimen can be identified in isolation, the situation is much more difficult, leading to polite and understandable questions by workers with only small series to work with. This has been aggravated by use of relative and weakly defined characters to diagnose these differences (e.g. Ivie 1985). Recently, Chalumeau and Touroult (2005) went so far at to consider E. pseudonomon a subspecies of E. glabratum. However, the definition of a subspecies generally includes "....and interbreeding successfully where their ranges overlap" (Lincoln et al. 1982), and there is no evidence of these two forms occurring together anywhere in their ranges. Therefore, they cannot be considered subspecies. In the absence of behavioral or genetic data most modern insect systematists consider two allopatric populations that exhibit consistent differences to have divergent evolutionary histories, and place them either as populations of the same taxon or recognize them as full species. After extensive work with these populations for (in the case of Ivie) nearly 30 years, we have found they consistently behave as species, and have identified several, albeit difficult, characters to distinguish them (see diagnosis under E. glabratum above). These differences correspond to a biogeographic boundary (the Anegada Passage), which divides the Greater and Lesser Antillean faunae, further strengthening our argument. We therefore return E. pseudonomon to full specific status.

DIAGNOSIS: See under E. glabratum. Length $9.5-17 \mathrm{~mm}$.

DISTRIBUTION: St. Thomas, St. John, Tortola, Guana (Valentine and Ivie, 2005), Virgin Gorda, Anegada. Puerto Rican record removed to E. mayesea.

\section{Key to species of Elaphidion of Puerto Rico and the Virgin Islands}

1. Third and fourth antennomeres spined on both internal and external apical angles..................................2

1 ' Third and fourth antennomeres spined only on internal angle ................................................................ 
2. Prosternal process parallel-sided, rounded apically, with caudad apex at median; length $30 \mathrm{~mm}$ or greater; Puerto Rico

2' Prosternal process widened and truncate apically, sometimes emarginate medially, median not most caudad point; length $25 \mathrm{~mm}$ or less; widespread.

E. conspersum (Newman)

3. Integument dark chocolate brown to black, with patches of white pubescence on head, pronotum and elytra; emargination between apical elytral spines obliquely truncate to weakly bisinuate so that sutural spine is shorter..... E. irroratum (L.)

3' Integument light brown to dark chocolate brown, with ochre to golden pubescence; emargination between apical elytral spines simply arcuate, both spines long, although outer may be longer...

4. Metafemoral apex spiniform, spine longer than basal metatibial width; antennomere 4 short relative to 5; apical spine of male antennomere 3 greater than $0.5 \times$ length of antennomere 4 ; apical spine of female antennomere 3 subequal to or longer than length of antennomere 4; setae of pronotal and elytral disk broader, rounded-blunt at apex

E. mayesae Ivie

4' Metafemoral apex dentiform, spine subequal to basal metatibial width; antennomere 4 longer relative to 5; apical spine of male antennomere 3 less than $0.5 \times$ length of antennomere 4 ; apical spine of female antennomere 3 distinctly shorter than antennomere 4; setae of pronotal and elytral disk narrow, acutely attenuate at apex

5. Lighter in color, setae generally distributed on elytral disc, allowing derm to show through between, always visible just mesad humeral umbone and between striae at level of metacoxa (Figs 15, 17); punctures of basal portion of elytral disc smaller (Fig. 19); Northern Virgin Islands ......... pseudonomon Ivie

5' Darker in color, setae clumped in dense patches, completely hiding derm, giving a distinct patterned appearance, density always visible just mesad humeral umbone and between striae at level of metacoxa (Figs 14, 16); punctures of basal portion of elytral disc larger (Fig. 18); St. Croix and Lesser Antilles .......

E. glabratum (Fabricius)

\section{Acknowledgements}

We would like to thank the curators listed in the Materials section above for the loan of specimens used in this paper. Richard S. Miller, LaDonna L. Ivie, Charyn J. Micheli, Ian Foley, Alistair Ramsdale and Katherine A. Marske helped with many portions of the project with discussions, encouragement and species character testing. Steven W. Lingafelter spent a great deal of time helping by debating the status of the populations of $E$. mayesae, greatly improving the overall conclusions. Carol Mayes was instrumental in running the ultraviolet light trap that provided the specimens critical to understanding the pseudonomon species complex. Steven Lingafelter, Frank Hovore and Charyn Micheli reviewed an earlier version of the manuscript. Figure 11 was drawn by Adam Rubenstein, Figures 12, 13 and 15 are by Nikki K. J. Miller. Field work was supported by NSF Grant DEB-93-00766 to Michael A. Ivie and Richard S. Miller. This is a contribution of the Montana Agricultural Experiment Station.

\section{References}

Blackwelder, R.E. (1946) Checklist of the coleopterous insects of Mexico, Central America, the West Indies, and South America, Part 4. United States National Museum Bulletin, 185, 551-763.

Browne, D. J., Peck, S.B., \& Ivie, M.A. (1993) Longhorn beetles (Coleoptera Cerambycidae) of Bahama Islands, with an analysis of species-area relationships, distribution patterns, origin of the fauna and annotated species list. Tropical Zoology, 6, 27-53.

Chalumeau, F. \& Touroult, J. (2004) Nouveaux Elaphidiini des Petites Antilles et notes diverses (Coleoptera, Cerambycidae). Lambillionea, 104, 751-755. 
Chalumeau, F. \& Touroult, J. (2005) Le Longicornes des Petites Antilles (Coleoptera, Cerambycidae). Taxonomie, Éthologie, Biogéographie. Pensoft Series Faunistica 51: 241.

Fabricius J.C. 1775. Systema Entomologiae. Lipsiae, $30+832$ pp.

Gilmour, E.F. (1968) The Coleoptera Cerambycidae of Curação, Aruba and Bonaire. Studies on the Fauna of Curação, $25,83-178,10 \mathrm{pls}$.

Ivie, M.A. (1985) Nomenclatural notes on West Indian Elaphidiini (Coleoptera: Cerambycidae). Pan-Pacific Entomologist, 61, 303-314.

Lincoln, R.J., Boxshall, G.A., \& Clark, P.F. (1982) A Dictionary of Ecology, Evolution and Systematics. Cambridge University Press, Cambridge, viii +298 pp.

Lingafelter, S.W. (1998) The Genera of Elaphidiini Thomson 1864. Memoirs of the Entomological Society of Washington, 20, 1-118.

Lingafelter, S.W. \& Micheli, C.J. (2004) New Species of Cerambycidae (Coleoptera) from Puerto Rico with records and notes for other species. Journal of the New York Entomological Society, 112, 37-55.

Linnaeus, C. (1767) Systema naturae, Tome I ,. Pars II, editio duodecima reformata. Holmiae, 533-1327 pp.

Linsley, E.G. (1963) The Cerambycidae of North America. Taxonomy and classification of the subfamily Cerambycinae, tribes Elaphidionini through Rhinotragini. University of California Publications in Entomology, 21, 1-165.

Martorell, L.F. (1976) Annotated food plant catalog of the insects of Puerto Rico. Agricultrual Experiment Station, University of Puerto Rico, Mayagez, 303 pp.

Monn, M.A., \& Giesbert, E.F. (1995) Checklist of the Cerambycidae and Disteniidae (Coleoptera) of the Western Hemisphere. Wolfsgarden Books, Burbank, xiv+ $420 \mathrm{pp}$.

Monn, M.A. \& Hovore, F.T. (2005) Electronic Version. 2005 Checklist of the Cerambycidae of the Western Hemisphere. http://www.hovore.com/pdf/Electronic_Checklist_2005.pdf. 393 pp. (accessed 20 June 2006).

Newman, E. 1841 Entomological notes. Entomologist 7, 110-112.

Wolcott, G.N. (1951) The insects of Puerto Rico. Coleoptera. Journal of Agriculture of the University of Puerto Rico, 32 [1948], 225-416.

Valentine, B.D. \& Ivie, M.A. (2005) Beetles: Coleoptera. In J. Lazell, Island: Fact and Theory in Nature. University of California Press, Berkeley, pp. $274-282$.

Villiers, A. (1980) Coloptres Cerambycidae des Antilles francaises, II. Cerambycinae. Annales de la Socit Entomologique de France, (N. S.) 16, 265-306.

Zayas, F.de. 1975 Revisin de la familia Cerambycidae. Academia de Ciencias de Cuba, Instituto de Zoologa, La Habana, Cuba, 443 pp. 


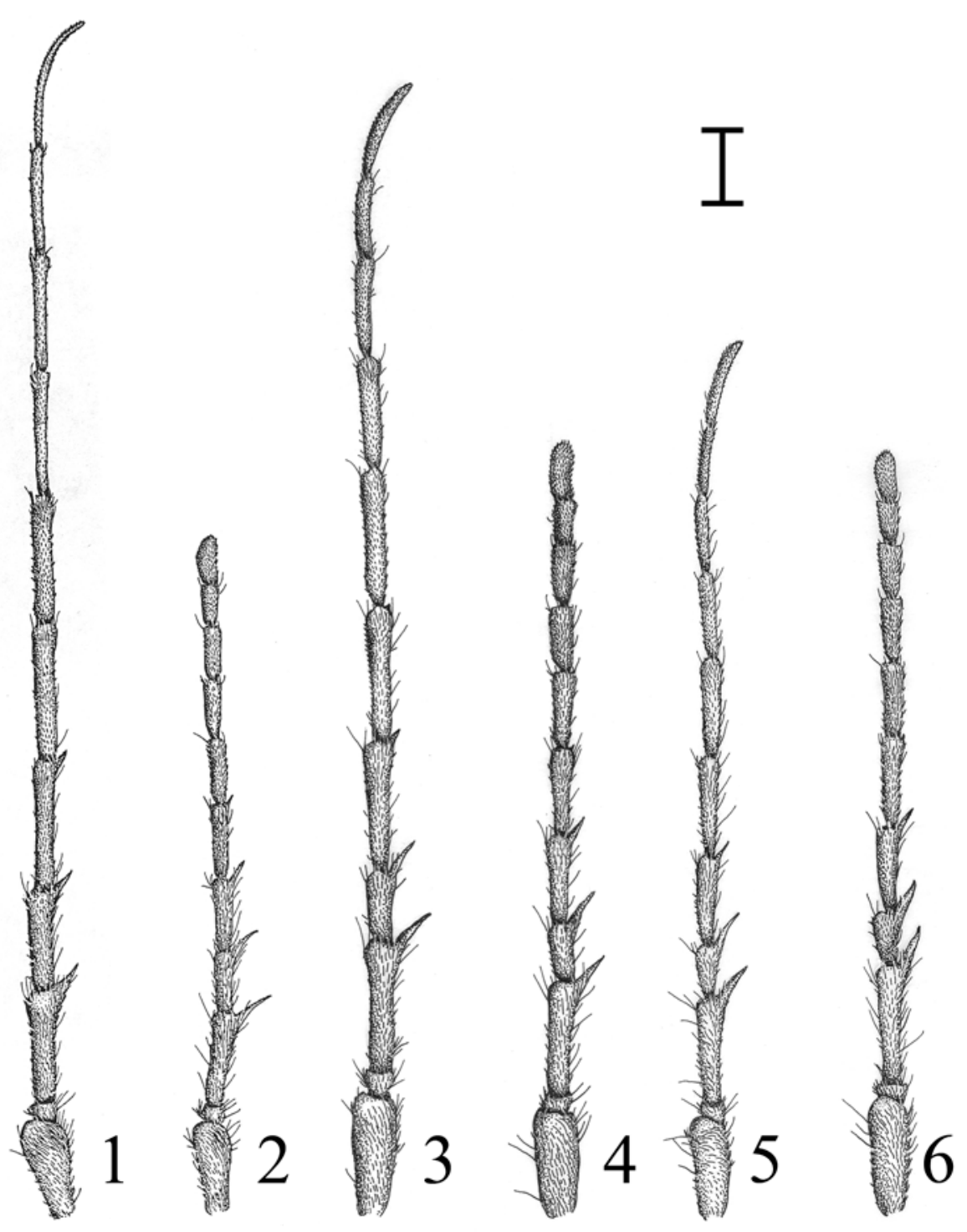

FIGURES 1-6. Antennae (scale bar = 1mm). 1. Elaphidion pseudonomon, male; 2. E. pseudonomon, female; 3. E. mayesae, male from St. Thomas; 4. E. mayesae, female from St. Thomas; 5. E. mayesae, male from Puerto Rico; 6. E. mayesae, female from Puerto Rico. 

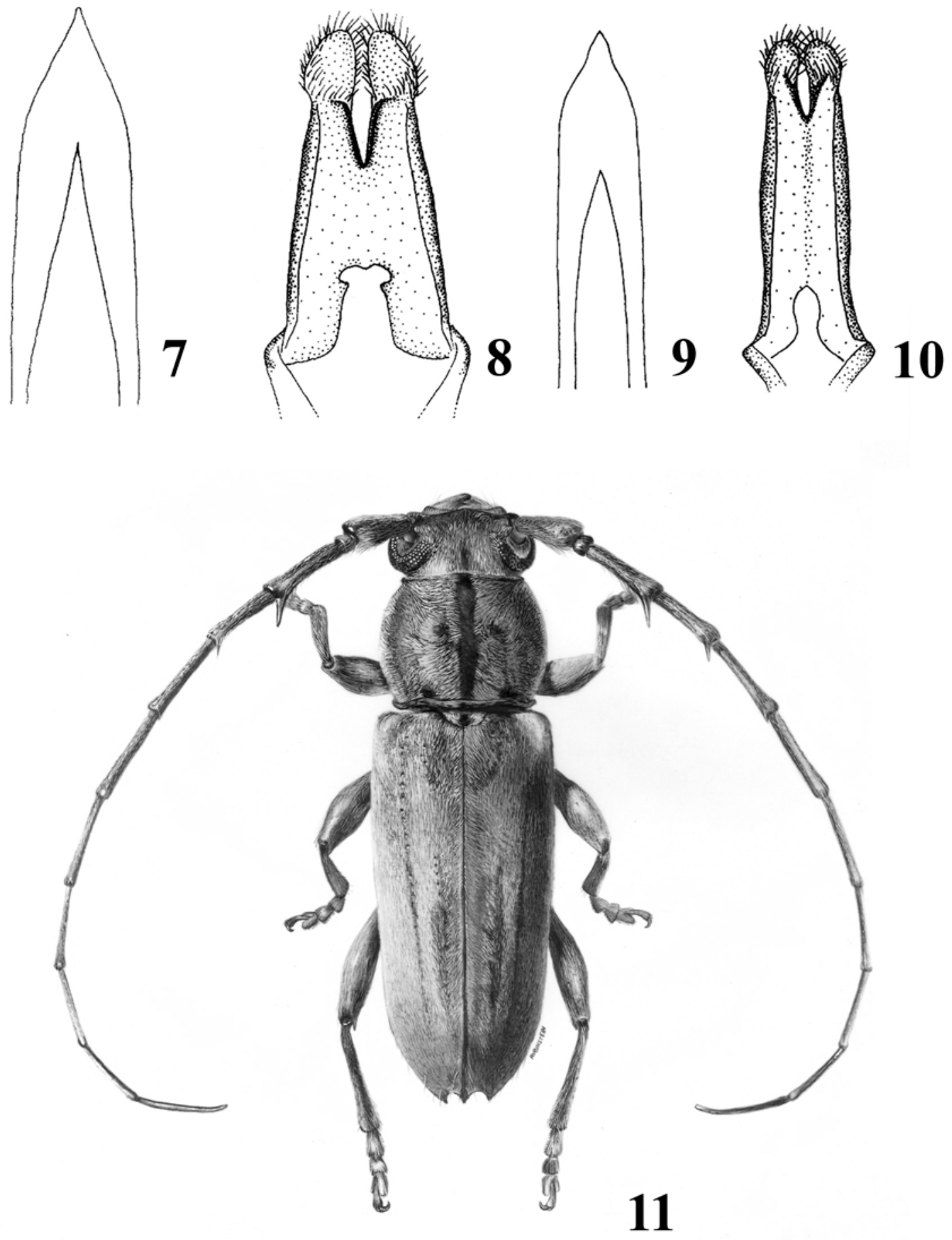

FIGURES 7-11. Elaphidion. 7. E. mayesae, from St. Thomas, aedeagus; 8. E. mayesae, from St. Thomas, parameres; 9. E. mayesae, from Puerto Rico, aedeagus; 10. E. mayesae, male from Puerto Rico, parameres; 11. E. pseudonomon, male, habitus. 

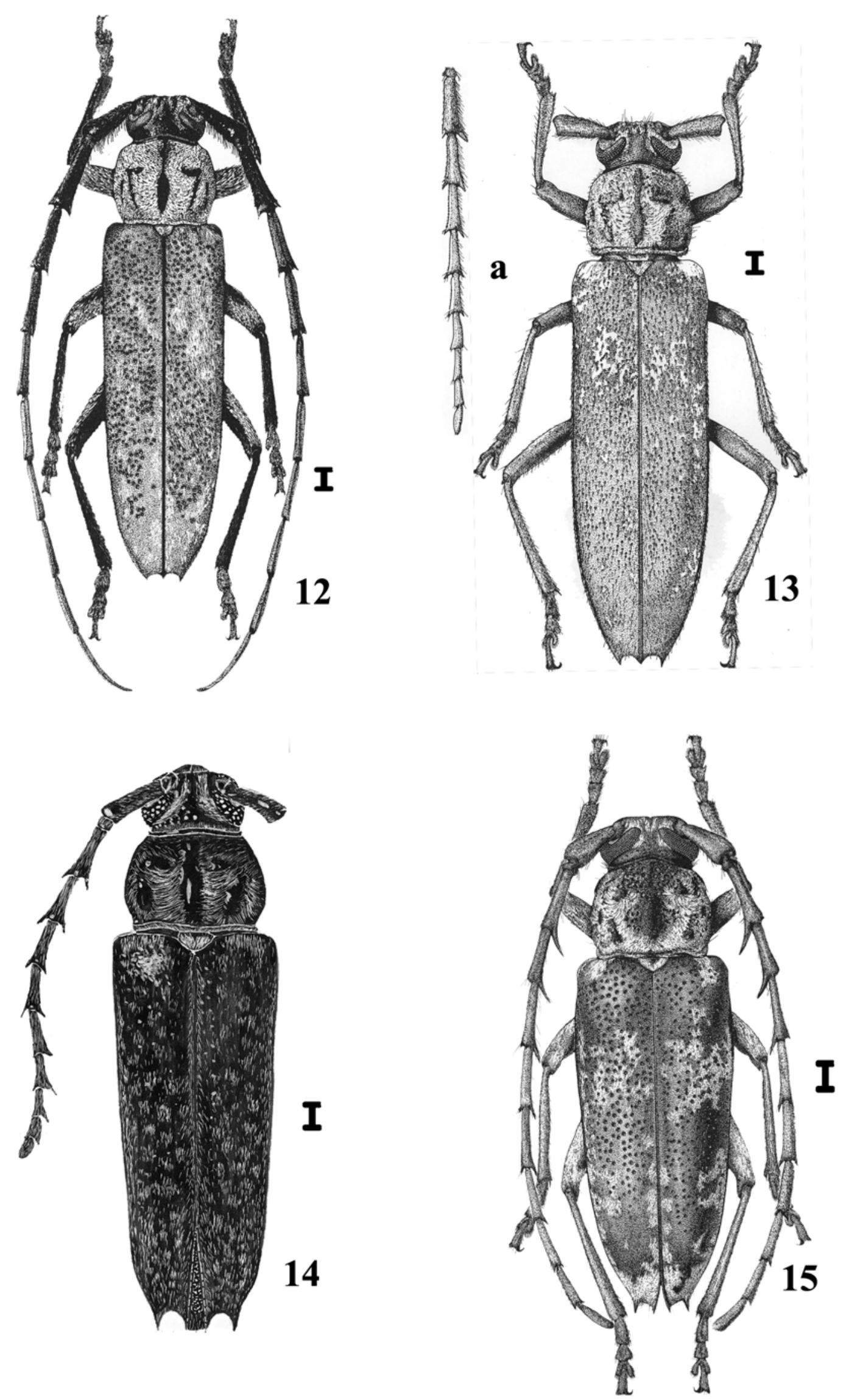

FIGURES 12-15. Elaphidion. 12. E. michelii, male; 13. E. michelii, female, a = antenna; 14. E. conspersum, female; 15. E. irroratum, female. Scale bars $=1 \mathrm{~mm}$. 

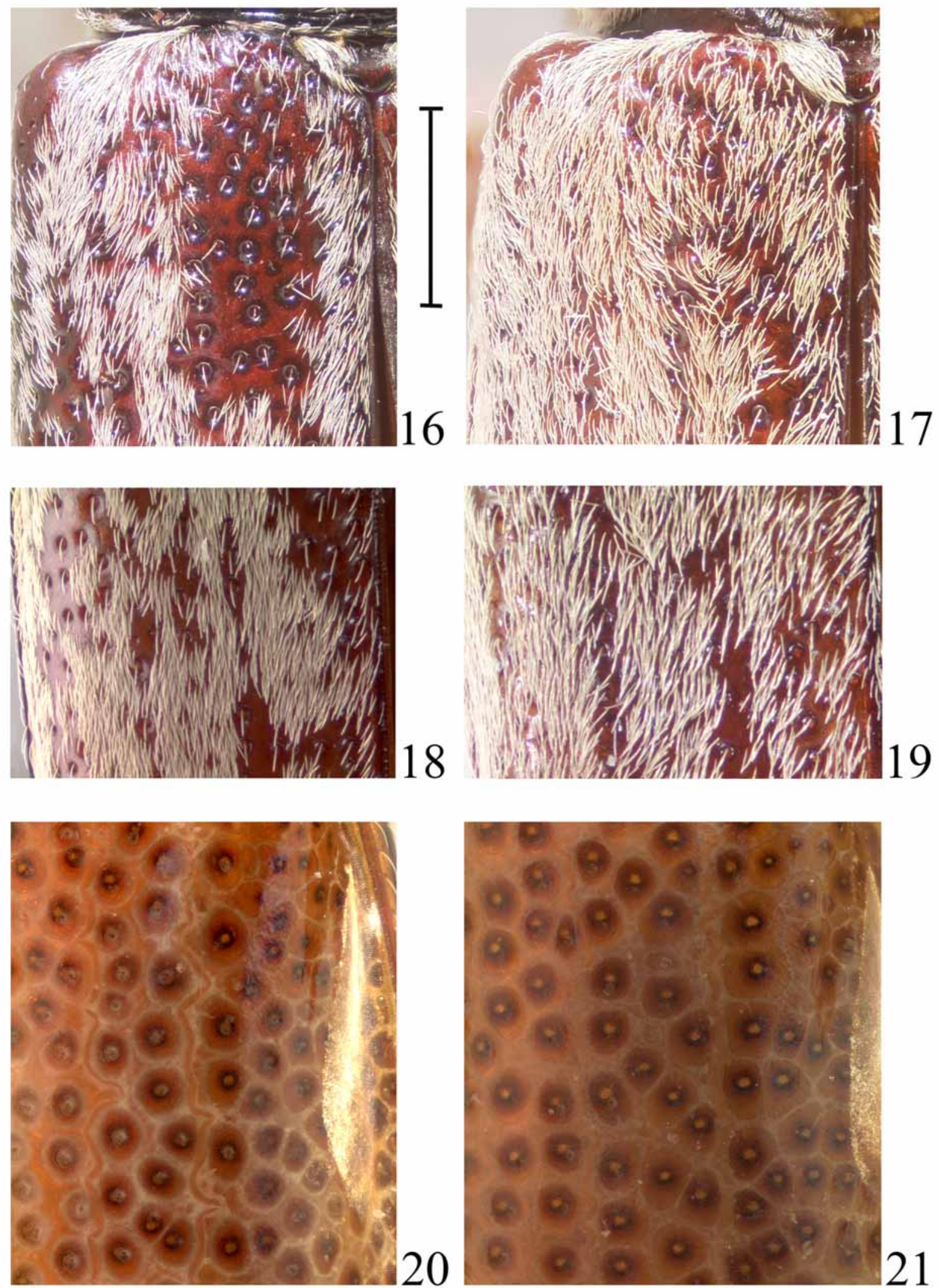

FIGURES 16-17. Dorsal view of left elytral base (scale bar =1mm). 16. E. glabratum; 17. E. pseudonomon.

FIGURES 18-19. Dorsal view of left mid-elytra (anterior to right) (scale bar =1mm). 18. E. glabratum; 19. E. pseudonomon.

FIGURES 20-21. Vental view of left elytron showing relative size of punctures. For orientation, golden area to right is the binding patch that opposes the dorsal epimeral sclerite (scale bar $=1 \mathrm{~mm}$ ). 20. E. pseudonomon; 21. E. glabratum. 